\title{
Desenvolvimento da avaliação em saúde: percursos e perspectivas
}

\author{
Development of health assessment: pathways \\ and perspectives
}
Desarrollo de la evaluación en salud: itinerarios y perspectivas

Lilia Blima Schraiber 1

doi: 10.1590/0102-311X00163820

Aproximando historiografia e estados da arte de três eixos das produções bibliográficas que estudam os serviços de saúde, os artigos deste Espaço Temático 1,2,3 produzem uma interlocução que motiva a reflexão em múltiplas direções. Entretanto, o que abordo nas considerações a seguir será o tipo de relação entre a avaliação de programas e de tecnologias e a investigação em serviços de modo mais global.

Os três textos trazem, em uma linha do tempo mapeadora das diversas produções nacionais e internacionais concernentes à avaliação em saúde, cuidadosa classificação dos conteúdos ora mais ora menos convergentes entre si, apontando para as especificidades de cada uma dessas correntes de pensamento em avaliação, em termos das principais contribuições dos estudos e das respectivas identidades teórico-metodológicas. Com isso, apresenta-se rico percurso da temática da avaliação em saúde em direção a perspectivas futuras.

A investigação em serviços de saúde é situada como a corrente que, sem intitular-se com ou definir o termo "avaliação", está voltada para os serviços em seus processos produtivos, englobando aí temas e questões de diferentes ordens quanto à articulação das práticas em saúde com o social.

Trata-se de um território mais amplo do que os outros dois subdomínios da avaliação em saúde: o da avaliação de programas e aquele das tecnologias. Lidos esses três artigos nessa ordem, produz-se a percepção de um percurso em que, progressivamente, a partir de um escopo global dos serviços de saúde, ocorrerá maior delimitação de objetos, com consequentes efeitos nas escolhas metodológicas e nos quadros teórico-conceituais. Vai-se produzindo um afunilamento e crescente especificação de parcelas daquele amplo território: os objetos de estudo e seus desenhos ganham recortes mais definidos e delimitados em movimento de especialização do conhecimento produzido.

Assim, essas três correntes de pensamento nos estudos sobre e em serviços de saúde têm em comum a realidade desses serviços como um todo na base de suas questões, e também têm em comum as perspectivas interdisciplinares como método de abordagem. Entretanto, à medida que se desenvolvem os estudos em avaliação de programas e mais ainda os de tecnologias, esses elos vão se tornando mais tênues a ponto de caber a indagação, nos dias mais atuais, sobre quais as relações entre as duas modalidades de avaliação, a de tecnologias e a de programas, e se as avaliações ainda pertencem ao mesmo escopo dos estudos da investigação em serviços.
1 Faculdade de Medicina, Universidade de São Paulo, São Paulo, Brasil.

\section{Correspondência} L. B. Schraiber Departamento de Medicina Preventiva, Faculdade de Medicina, Universidade de São Paulo. Av. Dr. Arnaldo 455, 20 andar, São Paulo, SP 01246-903, Brasil. liliabli@usp.br 
Se a preocupação historiográfica dos três textos reforça o reconhecimento dos elementos sócio-históricos comuns na origem desse movimento do conhecimento em saúde em direção aos serviços, em termos do desenvolvimento epistemológico e metodológico de cada corrente de pensamento, é a dispersão, o afastamento entre elas, na busca por especificidades individualizantes, o que mais chama a atenção, ainda que isso ocorra em perspectivas e ritmos desiguais entre si. A tal ponto isso se configura como uma relevante questão que os autores dedicam importantes reflexões sobre os limites e possibilidades dessas autonomias. No referencial de Bourdieu 4 adotado pelos autores do texto sobre avaliação de programas, tal dispersão, eu diria, reforçando o pensamento desses autores, impacta elementos centrais da constituição de um campo como, por exemplo, a formação do habitus de seus agentes.

Contudo, historicamente, tal busca por parcelamento e conformação segmentar autônoma de saber e prática pode ser vista como um traço da modernidade, com a progressiva valorização de uma sociedade de especialistas ${ }^{5}$. Trata-se da valorização do conhecimento cada vez mais especializado e da autoridade maior de quem o detém. O próprio reconhecimento da biomedicina moderna como saber de maior autoridade em termos de saúde é produto e produtor dessa valorização. Entretanto, por que a especialização, com autonomia do segmento que se especializa, é questão relevante, sobretudo, para nós da saúde coletiva?

É preciso considerar que quanto mais parcelas dos serviços de saúde se autonomizam para serem estudadas em si, como realidades independentes dos próprios serviços de que se originam e, ainda independentes das práticas sociais de que esses serviços também foram originados, mais se desqualificam saberes mais amplos e mais distante fica a relação entre a tecnologia, sua avaliação e o todo do serviço em que se insere. Em outros termos, fica mais difícil de compreender as tecnologias como recursos, como meios de alcançar outros fins que não elas próprias, como fins em si mesmas, como parte dos serviços e estes como parte da vida social 6 . Metodologicamente corre-se o risco de perdermos o entendimento das relações entre diversas tecnologias e delas com o social, dado o progressivo distanciamento em que passam a ser colocadas em sua autonomia relativamente a esse social.

Os serviços e os recursos tecnológicos em seu interior, tomados em si mesmos, processam uma inversão das relações: o que se origina em um todo maior como o serviço e, em última instância, se origina na vida social, não parecerá, por sua autonomia, ter essa origem. Em vez disso, muitas vezes inverte-se a relação, parecendo que a vida social ou o serviço é que deveriam se adequar à sua parte tecnológica, dado que são presididos por ela. Tais riscos, de natureza teórica e metodológica, terminarão por gerar conflitos com abordagens interdisciplinares, cuja existência, na saúde, é a de reestabelecer os nexos entre o conhecimento biomédico e aquele das ciências humanas e sociais, evitando a separação entre o mundo natural e o mundo social nos adoecimentos e nos sistemas de atenção. Essa perspectiva interdisciplinar foi outro elemento comum de percurso do conhecimento sobre os serviços de saúde e do qual as avaliações podem ir se dispersando.

Além disso, é preciso pensar sobre quais seriam os impactos desses processos para a própria Saúde Coletiva, espaço social que no Brasil acolheu a temática da avaliação em saúde. Como tem sido apontado na criação e no desenvolvimento histórico da saúde coletiva 7, ela teve desde seu princípio a interdisciplinaridade, em razão de uma consubstancialidade do técnico com o social. Nesse campo, a interdisciplinaridade e a relação saúde-sociedade operam como seus pilares de fundamentação. Nunca se tratou apenas de se somar disciplinas ou de se tentar fazer dialogar disciplinas quaisquer, mas reverter a redução epistemológica e teórica do mundo social ao território do biomédico.

Diante disso, quais seriam as possibilidades e os limites de perspectivas identitárias entre a avaliação em saúde e a saúde coletiva, de modo que garantisse a permanência da avaliação nesse espaço social de produção de saberes e práticas? De que modo manter o alinhamento com aquela interdisciplinaridade voltada à consubstancialidade tecnossocial? Até onde pode ir a especificidade de um segmento?

Um segmento de determinado todo se caracteriza por reproduzir esse todo em seu interior, não de forma mecânica, não apenas como repetição do todo, mas dentro da especificidade segmentar 1 . Assim, nas questões particulares e próprias dos programas e também nas da tecnologia, deve ser possível reconhecer sua contribuição para a reprodução dos serviços de saúde, mesmo que em conflito e instigando mudanças na estruturação e dinâmica desses serviços. Estudos cuja delimitação de questões, conformando, em qualquer das modalidades de avaliação, objetos autônomos relativamente aos 
serviços, ou que tornem epistemologicamente os serviços de saúde independentes do social, já não poderão reproduzir o todo a que pertencem e não corresponderão mais aos pilares de fundamentação da saúde coletiva. Esse é o convite à reflexão que trazem os artigos, quanto à relação entre a avaliação e a saúde coletiva.

\section{Informação adicional}

ORCID: Lilia Blima Schraiber (0000-0002-33260824).

\section{Referências}

1. Vieira-da-Silva LM, Furtado JP. A avaliação de programas de saúde: continuidades e mudanças. Cad Saúde Pública 2020; 36:e00237219

2. Martins M, Portela MC, Noronha MF. A avaliação de programas de saúde: continuidades e mudanças. Cad Saúde Pública 2020; 36:e00006720.

3. Novaes HMD, De Soárez PC. A Avaliação das Tecnologias em Saúde: origem, desenvolvimento e desafios atuais. Panorama internacional e Brasil. Cad Saúde Pública 2020; 36:e00006820.

4. Bourdieu P. Razões práticas. Sobre a teoria da ação. Campinas: Editora Papirus; 1996.

5. Arendt H. Entre o passado e o futuro. 7a Ed. São Paulo: Editora Perspectiva; 2003.

6. Mendes-Gonçalves RB. Práticas de saúde e tecnologia: contribuição para a reflexão teórica. In: Ayres JR, Santos L, organizadores. Saúde, sociedade e história. São Paulo: Editora Hucitec/ Porto Alegre: Rede Unida; 2017. p. 192-250.

7. Vieira-da-Silva LM, Paim JS, Schraiber LB. O que é saúde coletiva. In: Paim JS, Almeida-Filho $\mathrm{N}$, organizadores. Saúde coletiva: teoria e prática. Rio de Janeiro: MedBook; 2014. p. 3-12. 